\title{
Point mutations of the P53 gene, human hepatocellular carcinoma and aflatoxins*
}

\author{
Alexander L. Gerbes and Wolfgang H. Caselmann \\ Deparment of Medicine II. Klinikum Grosshadern, University of Munich, 81366 Munich. Germany \\ (Received 29 January 1992)
}

The tumor suppressor $p 53$ exerts important protective functions towards DNA-damaging agents. Its inactivation by allelic deletions or point mutations within the $P 53$ gene as well as complex formation of wildtype $p 53$ with cellular or viral proteins is a common and crucial event in carcinogenesis. Mutations increase the half-life of the $p 53$ protein allowing the immunohistochemical detection and anti-p 53 antibody formation. Distinct $G$ to $T$ point mutations in codon 249 leading to a substitution of the basic amino acid arginine by the neutral amino acid serin are responsible for the altered functionality of the mutant gene product and were originally identified in 8 of 16 Chinese and 5 of 10 African HCC patients. Both groups are frequently exposed to mycotoxin contaminations of their food. Today an average $P 53$ gene mutation rate of $25 \%$ is assumed for high-aflatoxin $\mathrm{B}_{1}$-exposure regions. This is double the rate observed in low-aflatoxin $\mathrm{B}_{1}$-exposure countries. Although many HCC patients displaying $P 53$ mutations also suffer from HBV infection, which itself can lead to rearrangements of $P 53$ coding regions or induce the synthesis of viral proteins possibly interacting with $p 53$, the specific $G$ to $T$ transversion within codon 249 of the $P 53$ gene seems to directly reflect the extent of aflatoxin $B_{1}$ exposure.

Key words: Tumor suppressor genes; Mycotoxins; Liver cancer

Hepatocellular carcinoma (HCC) represents one of the most common lethal tumors worldwide (1) and accounts for up to $30 \%$ of all types of malignant tumors in South East Asia and south and equatorial Africa. Chronic hepatitis B and C virus (HBV and HCV, respectively) infection, cirrhosis and aflatoxin $B_{1}$ exposure are considered the major aetiologic factors of HCC development (2). Molecular biological techniques have increasingly elucidated the pathogenic mechanisms which induce or maintain malignant hepatocyte transformation, and have provided evidence that inactivation of the tumor suppressor $p 53$ is a common and crucial event in carcinogenesis.

\section{The P53 gene - normal and deranged functions}

The P53 gene, located on the short arm of chromosome $17(17 \mathrm{pl}$ ), encodes a nuclear phosphoprotein

Correspondence to: Alexander L. Gerbes, M.D., or Wolfgang H. Caselmann. M.D., Dept. of Medicine II. Klinikum Grosshadern. University of Munich, Marchioninistr. 15, 81366 Munich, Germany.

*This article is cordially dedicated to Professor Gustav Paumgartner. M.D. on the occasion of his 60th birthday. 
which was originally identified as forming complexes with the large $T$ (umor) antigen of the Simian Virus 40 (3). Wildtype $p 53$ protein contains at least three functionally active domains (Fig. 1). The carboxyterminus harbours an oligomerizing function that allows $p 53$ tetramer formation (4) and a DNA-binding activity. A transcriptional trans-activator function resides in the aminoterminus $(5,6)$, which is involved in the control of transcription by regulating the interaction of DNA polymerase-alpha with other components of the DNA replication complex (7). Whereas wildtype $p 53$ is not required for normal ontogenic development in mice (8), it seems to exert pivotal protective functions as "guardian of the genome" (9): DNA-damaging agents like ultraviolet light, gamma-irradiation or certain chemotherapies (10) stimulate intracellular accumulation of $p 53$. In high concentrations $p 53$ inhibits DNA replication and cell growth thus providing sufficient time for DNA repair or allowing cytolysis, if the damage exceeds the restoring capacity of the cellular DNA repair systems (9).

Inactivation of the tumor-suppressing potential can be achieved by (1) allelic deletions or (2) point mutations within the $P 53$ gene as well as by (3) complex formation of wildtype $p 53$ with cellular or viral proteins (Fig. 2). Abnormal structure and expression of the P53 gene are observed in various hepatoma cell lines (11). HBV DNA integration can take place in the short arm of human chromosome 17 (12) near P53 sequences (13) and struclural rearrangements and subsequent aberrant transcription of the $P 53$ gene were found in both hepatocarcinoma cell lines and HCC tissues (14). In clonogenic assays using human fibroblast cell lines it was recently demonstrated that the disruption of one P53 gene, with the concomitant reduction of $p 53$ protein levels, was not sufficient to induce increased endogenous gene amplification considered to represent a preneoplastic condition in this system. However, the loss of both P53 alleles in these cells resulted in an increased rate of amplifications in association with the failure to arrest growth (15).

Point mutations are present in P53 cDNAs derived from astrocytomas, breast cancers, small cell lung cancers, esophageal cancers, osteosarcomas, rhabdomyosarcomas and colon cancers (7). Germ line P53 mutations occur in families with the Li-Fraumeni syndrome with autosomal dominantly inherited risk of diverse myesenchymal and epithelial neoplasms at multiple sites $(16,17)$. Almost $90 \%$ of these mutations are clustered in four regions of exons 5-8 of the P53 gene (18; Fig. 1). Point mutations affect distinct base pairs and result in the substitution of single amino acids. $G$ to $T$ transversions detected in codon 249 in human HCC $(19,20)$ lead to a substitution of the basic amino acid

\section{P53}

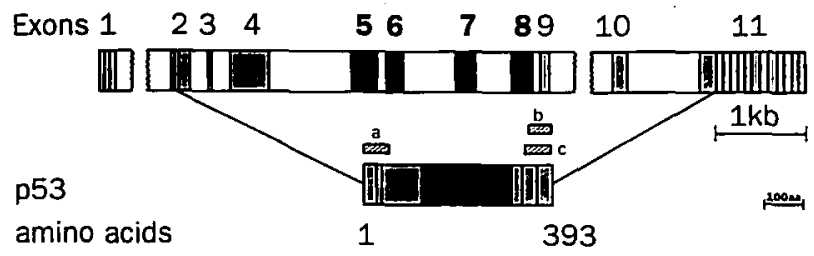

Fig. 1. Genomic organisation of human P53, which consists of 11 exons (numbers above) and 10 introns (white boxes). The hatched grey bars represent non-coding regions from which mRNAs are transcribed. The exons in black reflect preferred regions for point mutations. Interrupted white bars indicate a distance of 10 (intron 1) and approximately $2.5 \mathrm{~kb}$ (intron 10 ), respectively. The encoded $p 53$ protein is given below the gene sequence. a: trans-activating domain, b: oligomerizing domain, c: DNA-binding domain of $p 53$ protein. Size markers in $\mathrm{kb}$ (kilobases) and aa (aminoacids), respectively. The same pattern of coloration was chosen for correspoding exons and protein domains.

arginine by the neutral amino acid serin and may explain the functional alteration of the mutated protein. These mutations are all the more important since no mutations are observed in any other region of exons $5-8$ of $P 53$ or in non-tumorous tissues of the same patients. Furthermore, while no P53 mutations were detectable in early HCC stages as classified by histological evaluation, abnormalities of the P53 gene were shown in eight of 22 advanced HCCs (21). In six of seven cases of these advanced tumors, the $P 53$ gene aberrations were significantly associated with the loss of heterozygosity or alteration of a second tumor suppressor gene, the retinoblastoma $R b$ gene (21). This emphasizes the relevance of structural $P 53$ aberrations in advanced stages of disease and supports the hypothesis that an accumulation of mutations in tumor suppressor genes is important for tumorigenesis.

Tumor suppressor function

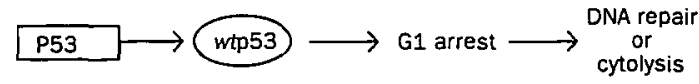

Inactivation by

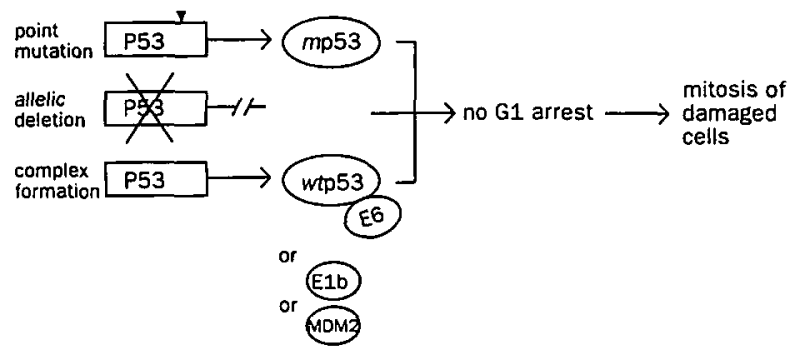

Fig. 2. Schematic illustration of the tumor suppressor function of wildtype $p 53$ (wtp53). Possible modes of inactivation of $p 53$ by point mutation $(\Lambda, m p 53)$, allelic deletion or complex formation with viral (E6, Elb) or cellular (MDM2) proteins and the consequences for the cell cycle are depicted below. 
Mutant $p 53$ proteins have lost the ability to act as tumor suppressors in transfection assays. While wildtype $p 53$ can suppress transformation in oncogene cooperation assays between c-myc and c-ras, mutated $p 53$ can gain transforming potential (22). Mutations increase the half life of the normal $p 53$ protein several times and result in the translation of a more stable protein that can be detected with immunohistochemical methods and induces anti-p53 antibody formation in more than $25 \%$ of HCCs (23). The diagnostic efficiency of anti-p53 antibody determination in detecting P53 gene mutation, however, remains to be elucidated. When monoclonal anti-p53 antibodies were used to stain tissue sections, overexpression of $P 53$ was shown in 9 of $58 \mathrm{HCC}$ specimens (24). This indirect detection of P53 mutations may, however, underestimate the actual frequency of gene mutations, because it will not recognize allelic deletions or codon stop introductions which lack protein translation. On the other hand, $p 53$ protein analysis may also overestimate the prevalence of gene mutations since other mechanisms of protein stabilization such as inactivation of p53-degrading enzymes or complex formation may play an important role. By forming heterologous oligomeric complexes with wildtype p53s mutated p53 inactivates wildtype $p 53$ and antagonizes its tumor suppressing potential $(25,26)$. The oncoproteins $E I b$ and $E 6$ of the adeno- and papilloma viruses, respectively, are further examples for $p 53$ inactivating binding partners (27), which are derived from DNA tumor viruses. Recently, co-immunoprecipitation experiments identified the MDM2 protein, which was encoded and originally described on a mouse double minute chromosome but overexpressed in human sarcomas, as the first cellular binding counterpart of $p 53$ (28, Fig. 1). Preliminary data suggest that no $p 53$ mutations occur if MDM2 gene amplification is present. As with viral oncoproteins, large amounts of MDM2 protein may complex and inactivate wildtype $p 53$ (28).

\section{Aflatoxins and $\mathrm{HCC}$}

There seems to be a geographical correlation between P53 codon 249 mutation in HCCs and aflatoxin $B_{1}$ uptake. The described point mutation was originally found in eight of 16 Chinese and five of 10 African patients $(19,20)$ with both groups living in regions with traditionally high exposure to mycotoxins. None of these mutations were detectable in 20 patients with HCCs recently studied in Great Britain (29). Only two of 13 HCC DNAs from Germany displayed a $C$ to $T$ and a $T$ to $A$ transversion, respectively, in codons 257 or 273 , but not in codon 249 (30). In all of the latter countries the environmental aflatoxin uptake is low. More recent studies claim a $P 53$ gene mutation rate of $25 \%$ for highaflatoxin $B_{1}$-exposure regions (31). This is twice the rate observed in low-aflatoxin $\mathrm{B}_{1}$-exposure countries, but still considerably less than previously assumed. Data from 167 patients with HCCs from various geographic areas differing in daily mycotoxin exposure also support the notion that codon 249 mutations of the $P 53$ gene are directly associated with high aflatoxin uptake (32). Aflatoxin $B_{l}$, the main food contaminating mycotoxin in China and Africa, is a fungal metabolite, mostly from inappropriately stored grain and is known as a hepatocarcinogen and epidemiologically defined risk factor for HCC development in different species $(32,33)$. The involvement of aflatoxins, bioactivated by $\mathbf{P}_{450}$ isoenzymes (34), in the observed $G$ to $T$ point mutations seems even more likely, because they specifically induce $G$ by $T$ substitutions by reacting almost exclusively with DNA guanines at the $\mathrm{N} 7$ position (35).

Since many HCC patients investigated for p53 mutations also suffer from $\mathrm{HBV}$ infection, the relative impact of these factors in the development of $\mathrm{HCC}$ is difficult to establish. Integration of HBV DNA during infection leads to manifold rearrangements of cellular DNA that can also affect $P 53$ coding regions. Furthermore HBV DNA integration induces the synthesis of $H B V$ transactivator proteins $(36-39)$ which may inactivate $p 53$ by complex formation. However, the specific $G$ to $T$ point mutation within codon 249 of the $P 53$ gene in HCC DNAs is not pathognomonic for all HCCs but seems to directly reflect the extent of aflatoxin $B_{1}$ exposure.

\section{Acknowledgements}

The research projects of ALG and WHC are supported by funds of the Deutsche Gesellschaft für Verdauungs- und Stoffwechselkrankheiten (Asche Stipendium to ALG) and a research grant of the Deutsche Forschungsgemeinschaft, Bonn (Ca 113/5-2; WHC). F. Anselm and C. Jüngst are thanked for the preparation of the manuscript.

\section{References}

I Kew MC. Tumors of the liver. In: Zakim D. Boyer TD, eds. Hepatology, Philadelphia: W.B. Saunders, 1990, 1206-40.

2 Colombo M. Hepatocellular carcinoma. J Hepatol 1992; 15 : 225-36.

3 Ludlow JW, DeCaprio JA. Huang CM. Lee WH. Paucha E, Livingstone DM. SV 40 large $T$ antigen binds preferentially to an under-posphorylated member of the retinoblastoma susceptibility gene product family. Cell 1989; 56: 57-65. 
4 Sturzbecher HW, Brain R, Addison C, et al. A C-terminal alphahelix plus basic region motif is the major structural determinant of p53 tetramerization. Oncogene 1992; 7: 1513-23.

5 Fields S, Jang SJ. Presence of a potent transcription activating sequence in the p53 protein. Science 1990; 249: 1046-9.

6 Raycroft L, Wu HY, Lozano G. Transcriptional activation by wild-type but not transforming mutants of the $P 53$ antioncogene. Science 1990; 249: 1049-51.

7 Marshall CJ. Tumor suppressor genes. Cell 1991; 64: 313-26.

8 Donehower LA, Harvey M, Slagle BL, et al. Mice deficient for p 53 are developmentally normal but susceptible to spontaneous tumors. Nature 1992: 356: 215-2l.

9 Lane DP. p53, guardian of the genome. Nature 1992: 358: 15-6.

10 Kastan MB, Onyekwere O, Sidransky D, Vogelstein B, Craig RW. Participation of $p 53$ protein in the cellular response to DNA damage. Cancer Res 1991; 51: 6304-11.

II Bressac B, Katherine M, Liang TJ. Isselbacher KJ, Wands JR, Ozturk M. Abnormal structure and expression of PS3 gene in human hepatocellular carcinoma. Proc Natl Acad Sci USA 1990; 87: 1973-7.

I2 Meyer M, Wiedorn KH, Hofschneider PH, Koshy R, Caselmann WH. A chromosome 17:7 translocation is associated with a hepatitis B virus DNA integration in human hepatocellular carcinoma DNA. Hepatology 1992; 15: 665-71.

1) Slagle BL, Zhou YZ, Butel JS. Hepatitis B virus integration event in human chromosome 17 near the $P 53$ gene identifies the region of the chromosome commonly deleted in virus-postive hepatocelIular carcinomas. Cancer Res 1991; 51: 49-54.

i4 Halevy O, Michalovitz D, Oren M. Different tumor-derived p53 mutants exhibit distinct biological activities. Science 1990; 250: 113-6.

15 Livingstone LR, White A, Sprouse J, Livanos E, Jacks T, Tisty TD. Altered cell cycle arrest and gene amplification potential accompany loss of wild-type p53. Cell 1992; 70: 923-35.

16 Malkin D, Frederick PL, Louise C, et al. Germ line P53 mutations in a familial syndrome of breast cancer, sarcomas and other neoplasms. Science 1990; 250: 1233-8.

17 Srivastava S, Zou Z, Pirollo K, Blattner W, Chang EH. Germline transmission of a mutated $P 53$ gene in a cancer-prone family with Li-Fraumeni syndrome. Nature 1990: 348: 747-9.

is Nigro JM, Baker SJ, Preisinger AC, et al. Mutations in the P53 gene occur in divers human tumour types. Nature 1989; 342 : $705-8$

19 Hsu IC, Metcalf RA, Sun T, Welsh JA, Wang NJ, Harris CC. Mutational hotspot in the P53 gene in human hepatocellular carcinomas. Nature 1991; 350: 427-8.

20 Bressac B, Kew M, Wands J, Ozturk M. Selective G to T mutations of $P 53$ gene in hepatocellular carcinoma from southern Africa. Nature 1991; 350: 429-31.

21 Murakami Y, Hayashi K, Horohashi S, Sekiya T. Aberrations of the tumor suppressor P53 and retinoblastoma genes in human hepatocellular carcinomas. Cancer Res 1991; 51: 5520-5.

22 Taylor WR, Egan SE, Mowat M, Greenberg AH, Wright JA. Evidence for synergistic interactions between ras, myc and a mutant form of $p 53$ in cellular transformation and tumor dissemination. Oncogene 1992; 7: 1383-90.

23 Mueller M, Volkmann M, Goeser T, et al. Anti-p53-Antikörper,
AFP-Spiegel und Hepatitis-Status beim hepatozellulaeren Karzinom. Z Gastroenterol 1993; 1: 97 (abstract).

24 Laurent-Puig P, Flejou JF. Fabre M, Bedossa P, Belghiti J, Gayral F. Franco D. Overexpression of P53; a rare event in a large series of white patients with hepatocellular carcinoma. Hepatology 1992; 16: 1171-5.

25 Jenkins J, Rudge K, Currie G. Cellular immortalization by a cDNA clone encoding the transformation-associated phosphoprotein $p 53$. Nature 1984; 312: 651-4.

26 Finlay C, Hinds P, Levine AJ. The P53 proto-oncogene can act as a suppressor of transformation. Cell 1989; 57: 1083-93.

27 Sarnow P, Ho Y, Williams J, Levine A. Adenovirus Elb-58 kD tumor antigen and SV 40 large tumor antigen are physically associated with the same $54 \mathrm{kD}$ cellular protein in transformed cells. Cell 1982; 28: 387-94

28 Barak Y, Oren M. Enhanced binding of a $95 \mathrm{kDa}$ protein in cells undergoing p53-mediated growth arrest. EMBO J 1992; 11 : 2115-21.

29 Challen C, Lunec J, Warren W, Collier J, Bassendine MF. Analysis of the P53 tumor-suppressor gene in hepatocellular carcinomas from Britain. Hepatology 1992: 16: 1362-6.

30 Kress S, Jahn UR, Buchmann A, Bannasch P. Schwarz M. P53 mutations in human hepatocellular carcinomas from Germany. Cancer Res 1992; 52: 3220-3.

31 Buetow KH, Sheffield VC, Minghua $Z$, et al. Low frequency of P53 mutations observed in a diverse collection of primary hepatocellular carcinomas. Proc Natl Acad Sci USA 1992; 89: 9622-6.

32 Ozturk M, Bressac B, Puisieux A, et al. P53 mutation in hepatocellular carcinoma after aflatoxin exposure. Lancet 1991: 338: 1356-9.

33 Lilleberg SL, Cabonce MA, Raju NR, Wagner LM, Kier LD. Alterations in the structural gene and the expression of P53 in rat liver tumors induced by aflatoxin $B_{1}$. Mol Carcinogen 1992; 6: 159-72.

34 Aoyama T, Yamano S, Guzelian PS, Elboin HV, Gonzalez FJ. Five of 12 forms of vaccinia virus-expressed human hepatic cytochrome $\mathbf{P}_{450}$ metabolically activate aflatoxin $\mathbf{B}_{1}$. Proc Natl Acad Sci USA 1990; 87: 4790-3.

35 Foster PL, Eisenstadt E, Miller JH. Base substitution mutations induced by metabolically activated aflatoxin $B_{1}$. Proc Natl Acad Sci USA 1983; 80: 2695-8.

36 Wollersheim M, Debelka U, Hofschneider PH. A transactivating function encoded in the hepatitis $B$ virus $X$ gene is conserved in the integrated state. Oncogene 1988; 3: 545-52.

37 Caselmann WH, Meyer M. Kekule AS, Lauer U, Hofschneider $\mathrm{PH}$, Koshy R. A novel trans-activator is encoded by hepatitis B virus $\mathrm{preS} / \mathrm{S}$ sequences integrated in human hepatocellular carcinoma DNA. Proc Natl Acad Sci USA 1990; 87: 2970-4.

38 Kekulé AS, Lauer U, Meyer M, Caselmann WH, Hofschneider $\mathrm{PH}$, Koshy $\mathrm{R}$. The preS2/S region of integrated hepatitis $\mathrm{B}$ virusDNA encodes a transcriptional rrans-activator. Nature 1990; 343: 457-61.

39 Meyer M, Caselmann WH, Schlüter V, Schreck R. Hofschneider $\mathrm{PH}$, Baeuerle $\mathrm{P}$. Hepatitis $\mathrm{B}$ virus trans-activator $\mathrm{mHBs}^{\prime}$ : activation of NF- $k B$, selective inhibition by antioxidants and integral membrane localization. EMBO J 1992: 11: 2991-3001. 